\title{
Analisis prakiraan kecepatan angin dengan menggunakan artificial neural network
}

\author{
Afrah Halawani*, Sutjianto, Mardiana Irawaty \\ Program Studi TeknikElektro SekolahTinggiTeknologiAdisutjipto \\ Email Korespondensi: *Afrah.halawani@gmail.com
}

\begin{abstract}
Prediction is one of the most important techniques in determining the resulting wind speed. The decision to predict is very important, because with predictions can calculate the average wind speed and a good prediction is an accurate prediction. The purpose of this research is to predict the wind speed using the neural network model to determine the wind speed in the following year. To predict wind speed, the author builds a wind speed prediction model using an artificial neural network (ANN) with a backpropagation learning algorithm. The scope of research data collection from BMKG Sleman. Therefore we need a method that is better than the load coefficient method. The results of this study show that the predictions of ANN wind speed in 2019 from January to December are close to the default data from the BMKG. Sleman and stay stable. And the average error percentage of ANN is $5 \%$.

Keywords: Wind speed, prediction, artificial neural network, backpropagation
\end{abstract}

\section{Pendahuluan}

Meteorologi adalah ilmu yang mempelajari tentang unsur-unsur cuaca yang diantaranya adalah suhu, kelembaban, tekanan udara, curah hujan, penguapan dan penyinaran matahari. Untuk membantu mengamati unsur-unsur tersebut dibutuhkan alat-alat yang bisa menunjang pengamatan secara cepat, tepat dan akurat.

Angin merupakan pergerakan udara yang dipicu oleh adanya perbedaan tekanan udara sebagai akibat dari perbedaan temperature di permukaan bumi, dinyatakan dalam arah dan kecepatan. Arah angin dinyatakan dalam derajat sedangkan kecepatan dinyatakan dalam satuan Internasional dan sering menggunakan table/scale yang lebih dikenal dengan sebutan "Beaufort Scale / Skala Beaufort" dengan satuan "knots". $(1 \mathrm{knots}=0.5 \mathrm{~m} / \mathrm{s}$ atau $1.8-1.9 \mathrm{~km} / \mathrm{jam})($ Zakir,2013).

Prediksi adalah salah satu teknik yang paling penting dalam mengetahui kecepatan angin yang dihasilkan. Keputusan dalam prediksi adalah sangatlah penting, karena dengan prediksi dapat menghitung kecepatan angin data yang didapat dan prediksi yang baik adalah prediksi secara akurat.

Untuk melakukan prediksi secara akurat maka diperlukan metode yang tepat pula. Artificial Neural Network atau biasa disebut juga jaringan syaraf tiruan adalah suatu metode komputasi yang meniru sistem jaringan saraf biologi. Metode ini menggunakan elemen perhitungan non-linier dasar yang disebut neuron yang diorganisasikan sebagai jaringan yang saling berhubungan, sehingga mirip dengan jaringan saraf manusia. Jaringan saraf tiruan ini dibentuk untuk memecahkan suatu masalah tertentu seperti 
pengenalan pola atau klasifikasi karena proses pembelajaran.

Berdasarkan latar belakang dan rumusan masalah diatas, maka tujuan penelitian ini adalah untuk meningkatkan akurasi prediksi kecepatan angin dengan melihat tingkat error dalam memprediksi besarnya kecepatan angin yang menggunakan Artificial Neural Network Backpropagation sebagai proses learningnya.

\section{Metode Penelitian}

Gambar 1 merupakan alur penelitian yang digunakan sebagai acuan dalam melaksanakan penelitian ini:

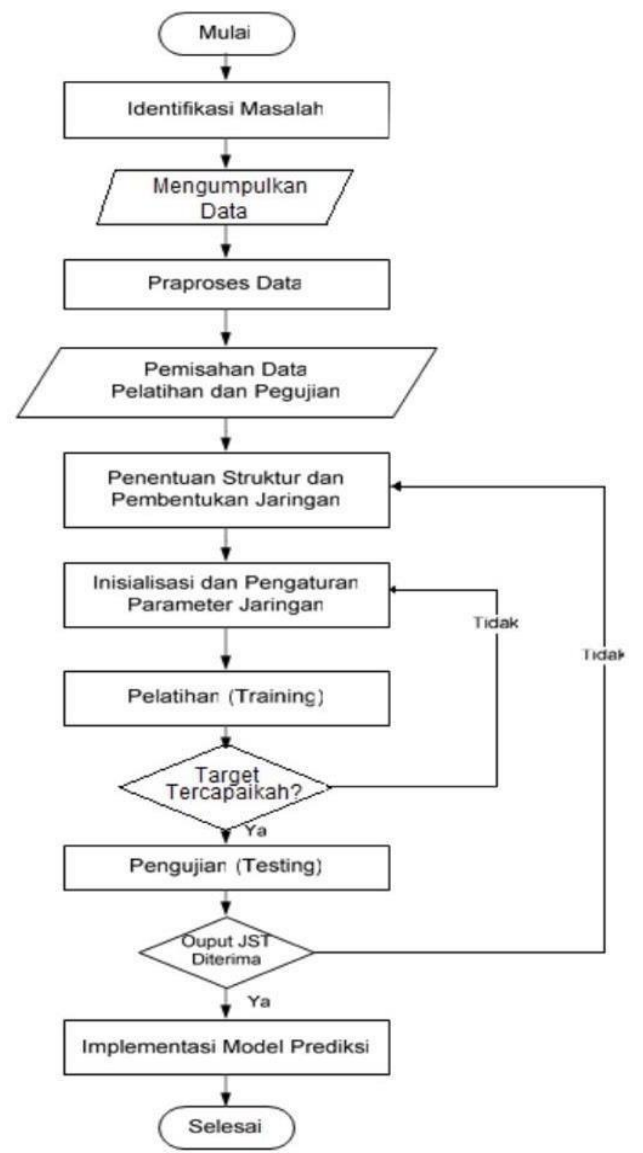

Gambar 1. Alur Penelitian

\subsection{Propagasi Balik (Backpropagation)}

Jaringan propagasi balik (backpropagation) merupakan salah satu algoritma yang sering digunakan dalam menyelesaikan persoalan atau masalah yang rumit. Hal ini dimungkinkan karena jaringan dengan algoritma ini dilatih (learned) dengan menggunakan metode belajar terbimbing. Pada jaringan diberikan sepasang pola yang terdiri atas pola masukan dan pola yang diinginkan. Ketika suatu pola diberikan kepada jaringan, bobot-bobot diubah untuk memperkecil perbedaan pola keluaran dan pola yang diinginkan. Latihan ini dilakukan secara berulang-ulang sehingga semua pola yang dikeluarkan jaringan dapat memenuhi pola yang diinginkan. Kelebihan metode ini mampu memformulasikan pengalaman dan pengetahuan peramal, serta sangat fleksibel dalam perubahan aturan perkiraan

Algoritma pelatihan jaringan syaraf tiruan propagasi balik terdiri atas 2 langkah, yaitu perambatan/propagasi maju dan perambatan/propagasi mundur. Langkah perambatan maju dan 
perambatan mundur ini dilakukan pada jaringan untuk setiap pola yang diberikan selama jaringan mengalami pelatihan. Jaringan propagasi balik terdiri atas 3 atau lebih lapisan/layer. Perbedaannya hanya pada jumlah lapisan tersembunyi yang dimilikinya, ada yang 1 lapisan ada yang lebih dari 1 lapisan.

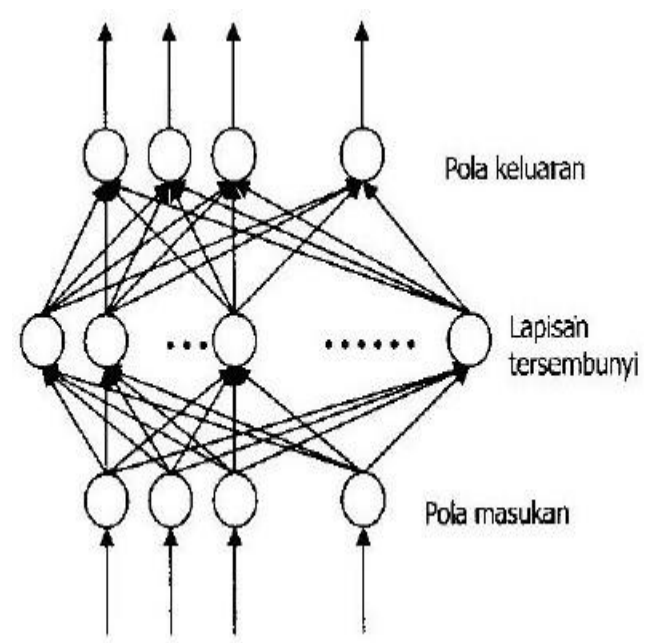

Gambar 2 Jaringan Propagasi Balik

Gambar diatas menunjukkan jaringan propagasi balik dengan 3 lapisan, bagian bawah gambar sebagai masukan, bagian tengah disebut sebagai lapisan tersembunyi dan bagian atas disebut lapisan keluaran. Ketiga lapisan ini terhubung secara penuh.

Perambatan maju dimulai dengan memberikan pola masukan ke lapisan masukan. Pola masukan ini merupakan nilai aktivasi unit-unit masukan. Dengan melakukan perambatan maju dihitung nilai aktivasi pada unit-unit di lapisan berikutnya. Pada setiap lapisan, tiap unit pengolah melakukan penjumlahan berbobot dan menerapkan fungsi sigmoid untuk menghitung keluarannya.

Untuk menghitung nilai penjumlahan berbobot digunakan rumus:

$$
S_{j}=\sum_{i=0}^{n} x_{i} w_{j i}
$$

\section{$\mathrm{Xi}=$ masukan yang berasal dari unit $\mathrm{i}$}

Wji=bobot sambungan dari unitike unitj. $\mathrm{Sj}$ =hasilpenjumlahanberbobot.

$$
f\left(S_{j}\right)=\frac{1}{1+e^{-S j}}
$$

(2) galat lapisan keluaran dapat

dihitung dengan rumus :

$$
\delta_{j}=\left(t_{j}-y_{j}\right) f^{\prime}\left(S_{j}\right)
$$

(3) $\delta \mathrm{j}=$ galat lapisan

tersembunyi

$$
\begin{array}{lll}
\mathrm{tj} & =\text { keluaranyangdiinginkandariunitj yj } & =\text { keluaran dari unit } \mathrm{j} \\
\mathrm{f}^{\prime}(\mathrm{Sj}) & =\text { turunan pertama dari fungsi sigmoid } \mathrm{Sj} & =\text { hasilpenjumlahan berbobot. }
\end{array}
$$

galat lapisan tersembunyi dapat dihitung dengan menggunakan rumus :

$$
\delta_{j}={ }_{k}\left[\sum \delta_{k} w_{k j} \cdot f^{\prime}\right]\left(S_{j}\right)
$$




$$
\Delta \mathrm{w}_{\mathrm{ji}}=a . \delta_{\mathrm{j}}, \mathrm{x}_{\mathrm{i}}
$$

unit ike unit j

$$
\begin{array}{ll}
\mathrm{A} & =\text { lajubelajar (learning rate) } \Delta \mathrm{j} \quad=\text { galat lapisan tersembunyi } \\
\mathrm{Xi} & =\text { masukan yang berasal dari unit } \mathrm{i} \\
& \text { Kesalahan (error) pada keluaran jaringan merupakan selisih antara keluaran sebenarnya }
\end{array}
$$

(current output) dan keluaran yang diinginkan (desired output) atau target.

\subsection{Mean Square Error (MSE)}

Jaringan syaraf tiruan propagasi balik dilatih dengan metode belajar terbimbing. Pada metode ini jaringan diberi sekumpulan pasangan pola yang terdiri dari pola masukan dan pola yang diinginkan. Pelatihan dilakukan berulang-ulang sehingga dihasilkan jaringan yang memberikan tanggapan yang benar terhadap semua masukannya

Perhitungan kesalahan (error) merupakan pengukuran bagaimana jaringan dapat belajar dengan baik, sehingga jika dibandingkan dengan pola yang baru akan dengan mudah dikenali. Kesalahan (error) pada keluaran jaringan merupakan selisih antara keluaran sebenarnya (current output) dan keluaran yang diinginkan (desired output) atau target. Selisih yang dihasilkan antara keduanya biasanya ditentukan dengan cara dihitung menggunakan persamaan :

Sum Square Error(SSE):

$$
S S E=\sum_{p} \sum_{j}\left(T_{j p}-Y_{j p}\right)^{2}
$$

Mean Square Error (MSE) :

$$
M S E=\frac{S S E}{n_{p} \cdot n_{j}}
$$

Root Mean Square Error (RMSE) :

$$
R M S E=\sqrt{M S E}
$$

(8) Tjp =nilaikeluaranyang

diinginkanatautargetjaringansyaraf

Yjp = nilai keluaran jaringansyaraf $n_{p} \quad=$ jumlah seluruh pola

$\mathrm{n}_{\mathrm{j}} \quad=$ jumlah keluaran

Kesalahan relatif adalah perbandingan antara kesalahan absolut terhadap ukuran sesuatu yang

diukur

|Pengukuran - Aktual $\mid$

Aktual

.(9) Untuk mengubah data ke skala baru,

untuk setiap data bisa dilakukan rumus :

$$
\mathrm{X}^{\prime}=\frac{X-X_{\min }}{X_{\max }-X_{\min }} *(B A-B B)+B B
$$

$\mathrm{X}=$ = Nilai data yang telah di transformasi $\mathrm{X}$

=Nilaidatasebelum ditransformasi Xmin

$=$ Nilai terkecil daridata

$\mathrm{Xmax}=$ Nilaiterbesar daridata 
$\mathrm{BA}=$ Batas atas data $\mathrm{BB}=$ =Batasbawahdata

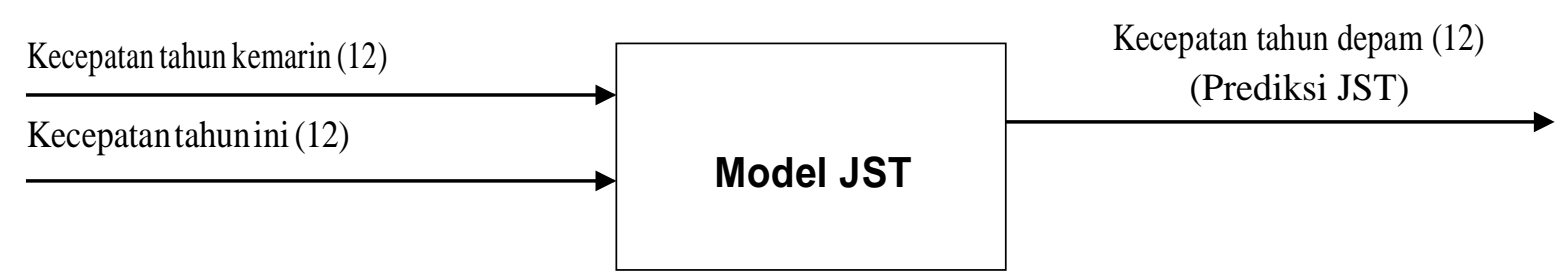

Gambar 3. Diagram Blok Model JST

Data yang di perlukan untuk melakukan analisis ini adalah:

Tabel 1. Data Kecepatan Angin Tahun 2016

Arah Angin, Kecepatan Angin Rata-rata per Bulan di Wilayah Kabupaten Sleman, 2016

\begin{tabular}{lll}
\hline Bulan & Arah Angin & Rata-rata \\
\hline 1. Januari & Timur Laut & $3 \mathrm{~m} / \mathrm{s}$ \\
2. Pebruari & Barat Laut & $3 \mathrm{~m} / \mathrm{s}$ \\
3. Maret & Timur Laut & $3 \mathrm{~m} / \mathrm{s}$ \\
4. April & Timur & $3 \mathrm{~m} / \mathrm{s}$ \\
5. Mei & Barat Laut & $3 \mathrm{~m} / \mathrm{s}$ \\
6. Juni & Timur Laut & $3 \mathrm{~m} / \mathrm{s}$ \\
7. Juli & Timur Laut & $3 \mathrm{~m} / \mathrm{s}$ \\
8. Agustus & Timur Laut & $3 \mathrm{~m} / \mathrm{s}$ \\
9. September & Barat Laut & $3 \mathrm{~m} / \mathrm{s}$ \\
10. Oktober & Utara & $3 \mathrm{~m} / \mathrm{s}$ \\
11. November & Utara & $3 \mathrm{~m} / \mathrm{s}$ \\
12. Desember & Barat Laut & $4 \mathrm{~m} / \mathrm{s}$ \\
\hline
\end{tabular}

Tabel 2. Data Kecepatan Angin Tahun 2017

Arah Angin, Kecepatan Angin Rata-rata per Bulan di Wilayah Kabupaten Sleman, 2017

\begin{tabular}{lll}
\hline Bulan & Arah Angin & Rata-rata \\
\hline 1. Januari & Barat & $3 \mathrm{~m} / \mathrm{s}$ \\
2. Pebruari & Barat Daya & $3 \mathrm{~m} / \mathrm{s}$ \\
3. Maret & Barat Daya & $3 \mathrm{~m} / \mathrm{s}$ \\
4. April & Barat & $3 \mathrm{~m} / \mathrm{s}$ \\
5. Mei & Barat Daya & $3 \mathrm{~m} / \mathrm{s}$ \\
6. Juni & Barat & $3 \mathrm{~m} / \mathrm{s}$ \\
7. Juli & Barat Daya & $3 \mathrm{~m} / \mathrm{s}$ \\
8. Agustus & Barat Daya & $3 \mathrm{~m} / \mathrm{s}$ \\
9. September & Barat Daya & $4 \mathrm{~m} / \mathrm{s}$ \\
10. Oktober & Barat Daya & $4 \mathrm{~m} / \mathrm{s}$ \\
11. November & Barat & $3 \mathrm{~m} / \mathrm{s}$ \\
12. Desember & Barat & $4 \mathrm{~m} / \mathrm{s}$ \\
\hline
\end{tabular}


Tabel 3. Data Kecepatan Angin 2018

Arah Angin, Kecepatan Angin Rata-rata per Bulan di
Wilayah Kabupaten Sleman, 2018
\begin{tabular}{lll}
\hline Bulan & Arah Angin & Rata-rata \\
\hline 1. Januari & Barat & $4 \mathrm{~m} / \mathrm{s}$ \\
2. Pebruari & Barat Daya & $3 \mathrm{~m} / \mathrm{s}$ \\
3. Maret & Barat Daya & $3 \mathrm{~m} / \mathrm{s}$ \\
4. April & Barat & $2 \mathrm{~m} / \mathrm{s}$ \\
5. Mei & Barat Daya & $2 \mathrm{~m} / \mathrm{s}$ \\
6. Juni & Barat & $3 \mathrm{~m} / \mathrm{s}$ \\
7. Juli & Barat Daya & $3 \mathrm{~m} / \mathrm{s}$ \\
8. Agustus & Barat Daya & $4 \mathrm{~m} / \mathrm{s}$ \\
9. September & Barat Daya & $4 \mathrm{~m} / \mathrm{s}$ \\
10. Otober & Barat Daya & $5 \mathrm{~m} / \mathrm{s}$ \\
11. November & Barat & $4 \mathrm{~m} / \mathrm{s}$ \\
12. Desember & Barat & $5 \mathrm{~m} / \mathrm{s}$ \\
\hline
\end{tabular}

\section{Hasil dan Pembahasan}

Kecepatan angin yang terjadi pada kurun waktu 3 tahun terakhir menampilkan grafik yang overload sehingga dilakukan pengujian jaringan syaraf tiruan agar dapat memprediksi kecepatan angin di tahun mendatang.

Setelah melakukan training dan menerapkan beberapa fungsi pelatihan didapat bahwa JST dengan fungsi pelatihan trainlm, model memberikan respon yang baik dengan menghasilkan nilai regression validation $=1$ dan test=1 pada epoch ke 175 . Kemudian nilai bobot yang telah didapat dan disimpan. Hasil pelatihan dengan beberapa fungsi pelatihan disampaikan dalam bentuk berikut:

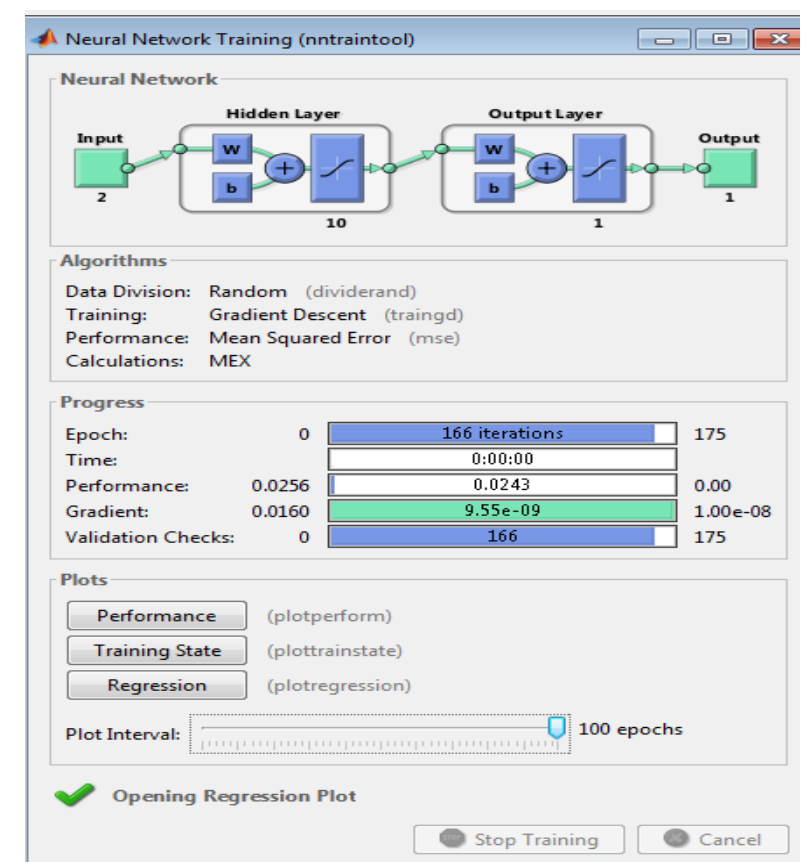

Gambar 4. Neural network pada feeder 


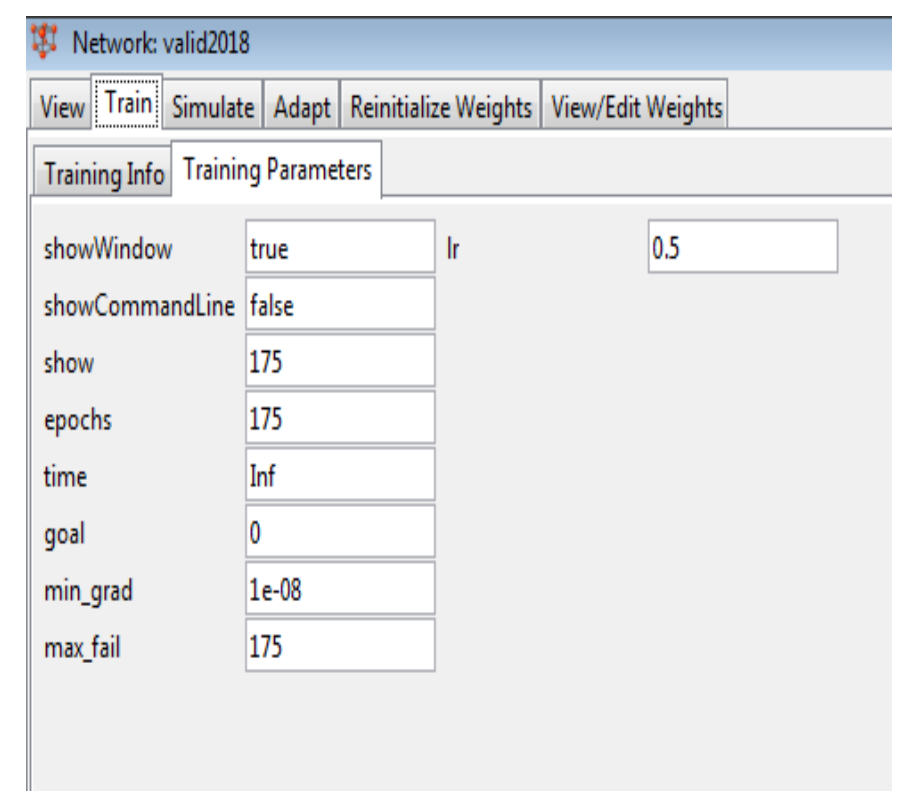

Gambar5. Training parameterspadafeed

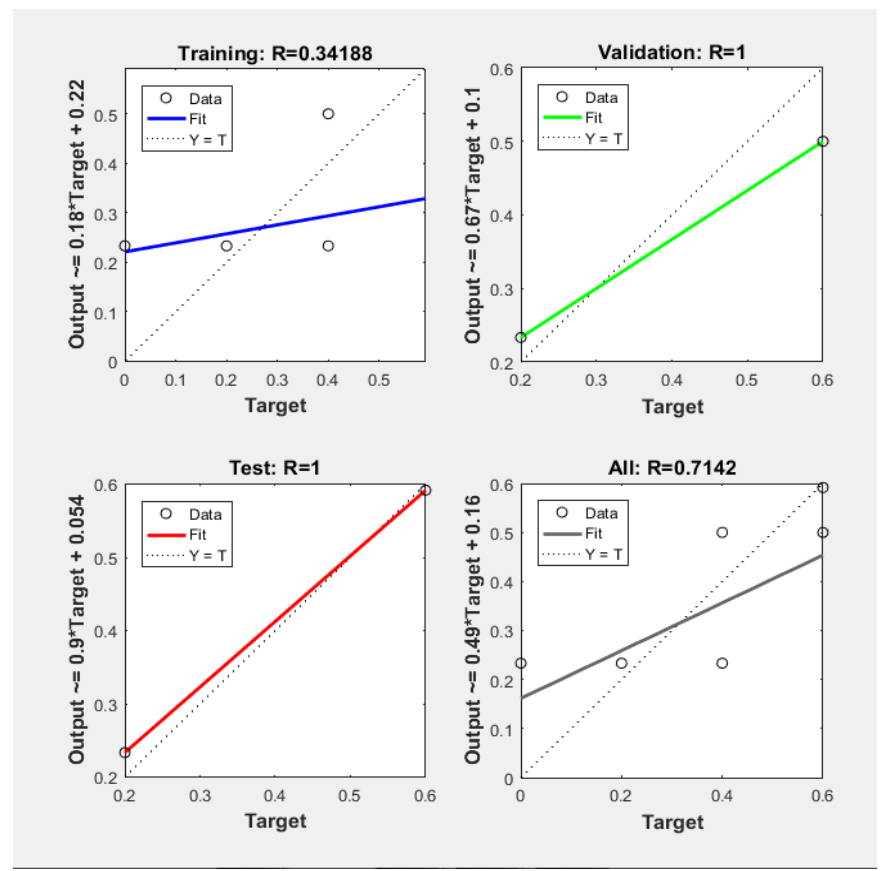

Gambar6. Grafik hasil Reggressionfeeder

Kecepatan angin rata-rata pada tahun 2018 sebesar $2 \mathrm{~m} / \mathrm{s}$ dan maksimal sebesar $5 \mathrm{~m} / \mathrm{s}$. Pada prediksi beban tahun 2019 prediksi rata-rata sebesar $1 \mathrm{~m} / \mathrm{s}$ dengan maksimum sebesar $3 \mathrm{~m} / \mathrm{s}$. Jika Data real dan hasil validasi prediksi pada JST mendekati atau sama, maka prediksi JST tahun 2019 merupakan hasil prediksi dengan tingkat keakuratan yang tinggi. Berdasarkan Tabel 3 diketahui bahwa perbedaan data real dan hasil validasi JST tidak terlalu jauh. Pada tahun 2018 kecepatan angin rata-rata sebesar $5 \mathrm{~m} / \mathrm{s}$ dan pada prediksi kecepatan angin 2019 sebesar $3 \mathrm{~m} / \mathrm{s}$. Jika data real dan hasil validasi prediksi pada JST mendekati atau sama, maka prediksi JST tahun 2019 merupakan hasil prediksi dengan tingkat keakuratan yang tinggi. 
Tabel 4. Hasil Prediksi Kecepatan Angin

\begin{tabular}{lllll}
\hline \multirow{2}{*}{ Bulan } & \multicolumn{3}{l}{ Kecepatan } & \multicolumn{3}{l}{ VALIDASI JSTPREDIKSI JST } \\
& Angin & 2018 & 2019 & MSE \\
& 2018 & & & \\
\hline Januari & $4 \mathrm{~m} / \mathrm{s}$ & $1.5 \mathrm{~m} / \mathrm{s}$ & $3 \mathrm{~m} / \mathrm{s}$ & 0.16667 \\
Februari & $3 \mathrm{~m} / \mathrm{s}$ & $1.5 \mathrm{~m} / \mathrm{s}$ & $1 \mathrm{~m} / \mathrm{s}$ & -0.033332 \\
Maret & $3 \mathrm{~m} / \mathrm{s}$ & $1.5 \mathrm{~m} / \mathrm{s}$ & $1 \mathrm{~m} / \mathrm{s}$ & -0.033332 \\
April & $2 \mathrm{~m} / \mathrm{s}$ & $1.5 \mathrm{~m} / \mathrm{s}$ & $1 \mathrm{~m} / \mathrm{s}$ & -0.23333 \\
Mei & $2 \mathrm{~m} / \mathrm{s}$ & $1.5 \mathrm{~m} / \mathrm{s}$ & $1 \mathrm{~m} / \mathrm{s}$ & -0.23333 \\
Juni & $3 \mathrm{~m} / \mathrm{s}$ & $1.5 \mathrm{~m} / \mathrm{s}$ & $1 \mathrm{~m} / \mathrm{s}$ & -0.033332 \\
Juli & $3 \mathrm{~m} / \mathrm{s}$ & $1.5 \mathrm{~m} / \mathrm{s}$ & $1 \mathrm{~m} / \mathrm{s}$ & -0.033332 \\
Agustus & $4 \mathrm{~m} / \mathrm{s}$ & $1.5 \mathrm{~m} / \mathrm{s}$ & $3 \mathrm{~m} / \mathrm{s}$ & 0.16667 \\
September & $4 \mathrm{~m} / \mathrm{s}$ & $1 \mathrm{~m} / \mathrm{s}$ & $3 \mathrm{~m} / \mathrm{s}$ & -0.10004 \\
Oktober & $5 \mathrm{~m} / \mathrm{s}$ & $3 \mathrm{~m} / \mathrm{s}$ & $3 \mathrm{~m} / \mathrm{s}$ & 0.099962 \\
November & $4 \mathrm{~m} / \mathrm{s}$ & $1.5 \mathrm{~m} / \mathrm{s}$ & $3 \mathrm{~m} / \mathrm{s}$ & 0.16667 \\
Desember & $5 \mathrm{~m} / \mathrm{s}$ & $3 \mathrm{~m} / \mathrm{s}$ & $3 \mathrm{~m} / \mathrm{s}$ & 0.0083747 \\
\hline
\end{tabular}

\section{Kesimpulan}

Bedasarkan pada proses analisa itu sendiri dapat ditarik beberapa kesimpulan yaitu bahwa kecepatan angin di Sleman D.I Yogyakarta tahun 2018 dapat di hitung menggunakan software Matlab dengan memanfaatkan Neural Network Software Matlab 2016 dapat dijadikan salah satu metode untuk melakukan perkiraan kecepatan angin. Dengan metode ANN dapat memberikan manfaat bagi penulis untuk memprediksi kecepatan angin setahun kedepan dan dapat dijadikan sebagai salah satu bahan literatur yang dapat digunakan sebagai pembuatan alat. Perbedaan arsitektur JST pada tiap- tiap unit karena bobot awal pelatihan diperoleh secara acak. Setelah dilakukan pelatihan dengan antara 150-200 iterasi (perulangan), didapatkan nilai (MSE) Mean Square Error yang berbeda- beda yaitu 0.16667 dan hasil dari prakiraan ini mendekati akurat.

\section{Ucapan terimakasih}

Teruntuk kedua orangtuaku, bapak dan Ibu. saya persembahkan untuk kalian berdua. Dua orang yang selalu berjuang mempertaruhkan segalanya demi anak-anaknya. Dua orang yang selalu memberihkan doa, kasih sayang dan perlindungan kepadaku. Hanya kata terimakasih yang bisa ku ucapkan yang sangat tak sebanding dengan jasa dan kasih sayang kalian. Teruntuk Pak Ir. Sutjianto S., M.T. dan Bapak Catur Budi S.T., M.T. Sebagai pembimbing, yang telah sabar dan penuh pengertian dalam membimbing dan memberikan ilmunya

\section{Daftar Pustaka}

[1] Akhmad Fadholi.(2013). "Pemanfaatan Suhu Udara dan Kelembapan Udara Dalam Persamaan Regresi Untuk Simulasi Prediksi Total Hujan Bulanan Di Pangkal Pinang”. Pangkal Pinang.

[2] Akhmad Fadholi. (2013), "Analisis data Arah dan Kecepatan Angin Landas Pacu. (Runway) Menggunakan aplikasi Windrose Plot (WRPLOT"), Pangkal Pinang.

[3] Anggit Bimo.(2020). "Analisis Prakiraan Beban Listrik Wilayah Yogyakarta dengan Jaringan Syaraf Tiruan" Yogyakarta

[4] Desvina, A. P., \& Anggriani, M.(2015). "Peramalan Kecepatan Angin Di Kota Pekanbaru Menggunakan Metode Box-Jenkins. Jurnal Sains Matematika Dan Statistika". Pekanbaru.

[5] Ema Sastri Puspita, Liza Yulianti. (2016). "Perancangan Sistem Peramalan Cuaca Berbasis Logika Fuzzy". Bengkulu.

[6] Gunawan D, Sudarsono, Wahyuono S, Donatus IA, Purnomo. (2011). "Cuaca: Hasil Penelitian, Sifat-sifat dan Penggunaan”. https://socs.binus.ac.id/2012/07/26/konsep-neural-network diakses pada 15 April 2020 
[7] H. S. Nogay. (2012), "Application of Artificial Neural Network s for short term wind speed forecasting in Mardin, Turkey". Afrika Selatan

[8] Saputra Rizqilillah. (2018). "Rancang Bangun Alat Penentu Arah Landing Pesawat Menggunakan Anemometer JL FS2" Yogyakarta.

[9] Syukri , Samsuddin. (2018) "Pengujian Algoritma Artificial Neural Network (ANN) Untuk Prediksi Kecepatan Angin ". Universitas Serambi Mekkah.

[10] Syukur Abdul. (2016). "Prediksi Kecepatan Angin Menggunakan Model Artificial Neural Network Berbasis Adaboost" Semarang. https://hwsmartsolution.com/blog/2016/02/18/metode-lvq-learningvector-quantization- untuk-pengenalan-pola/ diakses pada 20 April 2020 
